\title{
O DISCURSO NÃO VERBAL NAS MANIFESTAÇÕES SOCIAIS: Argentina, Brasil e Espanha
}

Andrea Galvão de Carvalho

(Colégio Pedro 11)

https://orcid.org/0000-0001-8650-2885

\section{RESUMO}

Este estudo visa analisar os mecanismos de funcionamento da linguagem não verbal nas manifestações sociais de rua no Brasil, na Argentina e na Espanha no período de abril a agosto de 2013 visando identificar práticas discursivas imagéticas utilizadas pelo sujeito-manifestante no ato do protesto. Nosso objetivo principal é, entendendo os protestos como práticas discursivas, apresentar como os sujeitos-manifestantes expressam suas demandas e críticas sócio-políticas através do não verbal. No que se refere ao aporte teórico, a pesquisa tem como base a escola francesa de Análise do Discurso (AD), a partir dos trabalhos de Pêcheux (2010, 2006) e Orlandi (2009), além do conceito de carnavalização proposto por Bakhtin (2013). Para a análise do não verbal, temos como fundamentação os estudos de Souza (2012, 2001), Courtine (2013) e Davallon (1999).

PALAVRAS-CHAVE: protesto; não verbal; Análise do Discurso. 


\title{
THE NON VERBAL IN SOCIAL MANIFESTATIONS: Argentina, Brazil and Spain
}

\begin{abstract}
This study aims to analyze the mechanisms of non-verbal language functioning in street social manifestations in Brazil, Argentina and Spain from April to August 2013, in order to identify the visual discursive practices used by the protesting subject in protest. Our main objective is, understanding the protests as discursive practices, to present how the protester-subjects express their demands and socio-political criticisms through the nonverbal. As for the theoretical contribution, the research is based on the French School of Discourse Analysis (AD), based on the works of Pêcheux $(2010,2006)$ and Orlandi (2009), in addition to the concept of carnivalization proposed by Bakhtin (2013). For the non-verbal analysis, we have as basis the studies of Souza (2012, 2001), Courtine (2013) and Davallon (1999).

KEYWORDS: protest; non verbal; Discourse Analysis.
\end{abstract}

\section{Nosso caminhar}

Pensar as manifestações sociais na atualidade é pensar o espaço citadino como lócus de expressão do manifestante, que se utiliza de distintas práticas discursivas para expor suas críticas e reivindicações. Nesse contexto, o presente artigo busca discutir a presença do não verbal em manifestações sociais de rua realizadas na Argentina, no Brasil e na Espanha no período de abril a agosto de 2013. Nosso objetivo é analisar os mecanismos de funcionamento da linguagem não verbal em manifestações sociais de rua buscando identificar a presença do imagético nas práticas discursivas utilizadas pelo sujeito-manifestante no ato do protesto. A proposta é estabelecer como o sujeito-manifestante utiliza a imagem 
como forma de se expressar e de ocupar sua posição discursiva através de distintos artefatos que muitas vezes coadunam o verbal e o não verbal.

Visando alcançar nossos objetivos, trabalhamos com a Análise do Discurso (doravante AD) com base nos estudos de Pêcheux (2006) e Orlandi (2009), além de explorarmos o conceito de carnavalização proposto por Bakhtin (2013). No que tange o estudo do não verbal, temos como fundamentação teórica Souza (2001), Courtine (2013) e Davalon (1999).

O corpus deste estudo é formado por imagens de manifestações coletadas em sites de busca, de jornais e de revistas online e também em versões impressas. Nosso recorte abarca o período de abril a agosto de 2013 e foram selecionadas manifestações que têm em comum três características: organização horizontal, sem participação de políticos ou sindicatos; fossem manifestações críticas aos governos vigentes e tivessem sido organizadas, inicialmente, via internet/redes sociais para em um segundo momento ocupar as ruas.

O percurso traçado para este artigo organiza-se na apresentação dos pressupostos teóricos que embasam as discussões propostas, no conhecimento das condições de produção que permearam as manifestações e nas análises do não verbal nesses movimentos.

\section{A Análise do Discurso e o não verbal}

Ao analisar os enunciados das manifestações sociais com foco no não verbal, baseamo-nos na $\mathrm{AD}$, posto que tal teoria, ao estudar o discurso, busca compreendê-lo na relação de significação tendo a língua como lugar da incompletude, da tensão, da contradição, que admite falhas e deslizamentos. A AD não tem um objeto linguístico como elemento de estudo, mas "um objeto sócio-histórico em que o linguístico intervém como pressuposto" (ORLANDI, 1998b, p.17).

O sentido para a $\mathrm{AD}$ está intrinsecamente relacionado às condições sócio-históricas de produção do discurso. "O discurso não é fechado em si mesmo e nem é do domínio exclusivo do locutor: aquilo que se diz significa em relação ao que não se diz, ao lugar social do qual se diz, para quem se diz, em relação a outros discursos" (ORLANDI, 2011, p.83).

Pêcheux destaca que "não há discurso sem sujeito e não há sujeito sem ideologia: o indivíduo é interpelado em sujeito pela ideologia e é assim que a língua faz sentido". Dessa forma, o sujeito do discurso, por ser um indivíduo interpelado pela ideologia, não é fonte absoluta do sentido, posto que dentro do seu discurso estão outros dizeres. 
No processo de significação, sentido e sujeito não se separam, entretanto para fazer sentido é necessário que o sujeito esteja inscrito em uma Formação Discursiva (FD). "São as formações discursivas que, em uma formação ideológica e levando em conta uma relação de classe, determinam 'o que pode e deve ser dito' a partir de uma posição dada em uma conjuntura dada" (BRANDÃO, 2004, p.48). Por formação ideológica entende-se uma formação imaginária constituída pelas atitudes e representações diretamente relacionadas às FDs.

Pêcheux (2006) estabelece FD como o lugar de constituição do sentido e da identificação do sujeito; é na FD que o sujeito se reconhece.

(...) as palavras, expressões, proposições etc., mudam de sentido segundo as posições sustentadas por aqueles que as empregam, o que quer dizer que elas adquirem seus sentidos em referência a essas posições, isto é, em referência às formações ideológicas (...) nas quais essas posições se inscrevem. Chamaremos, então, formação discursiva aquilo que, numa formação ideológica dada, isto é, a partir de uma posição dada numa conjuntura dada, determinada pelo estado da luta de classes, determina o que pode e deve ser dito (...). Isso equivale a afirmar que as palavras, expressões, proposições etc., recebem seus sentidos da formação discursiva na qual são produzidas (...). (Pêcheux, 2006, p.146)

$\mathrm{Na}$ produção de um discurso, o sujeito promove uma relação do discurso em formulação (que está sendo produzido no momento) com a memória discursiva, ou seja, com todos os dizeres que já foram ditos. Desta maneira, podemos dizer que só há o dito porque há um já dito, conforme assegura Pêcheux (1999, p.52):

A memória discursiva seria aquilo que, face a um texto que surge como acontecimento a ler, vem restabelecer os 'implícitos' (quer dizer, mais tecnicamente, os pré-construídos, elementos citados e relatados, discursos-transversos, etc.) de que sua leitura necessita: a condição do legível em relação ao próprio legível.

A memória que interessa a Análise do Discurso não é a memória psicológica, é a memória discursiva, é a "memória social, coletiva, em sua relação com a linguagem e a história" (COURTINE, 2006, p.2).

Para Orlandi (2009), a memória, quando pensada no discurso, é interdiscurso, é a memória afetada pelo esquecimento, ao longo do dizer. Interdiscurso é "todo o conjunto de formulações feitas já esquecidas que determinam o que dizemos" (ORLANDI, 2009, p.33). Assim, não há dis- 
curso que não se relacione com o já dito, é a partir de sentidos já existentes que o sujeito pode formular novos sentidos.

O funcionamento do discurso se estabelece, então, na tensão constante entre os processos parafrásticos e polissêmicos (ORLANDI, 2007). Os processos parafrásticos se caracterizam pela permanência, pela continuidade, são aqueles no qual o dizer se apresenta em diferentes formulações, mas com um mesmo sentido. A polissemia, por sua vez, é a ruptura, a transformação, a multiplicidade de sentidos. Segundo Orlandi (1984), a paráfrase está associada à produtividade e os processos polissêmicos à criatividade. A produtividade pertence à constituição dos dizeres, ao interdiscurso, à memória, porque não há sentido sem repetição, sem sustentação no saber discursivo. A criatividade refere-se à formulação dos discursos e, por conseguinte, é inerente a sua existência discursiva, pois se os sentidos não fossem múltiplos, não pudessem ser outros, não haveria a necessidade do dizer.

(...) todo discurso se faz nessa tensão: entre o mesmo e o diferente. Se toda vez que falamos, ao tomar a palavra, produzimos uma mexida na rede de filiação dos sentidos, no entanto, falamos com palavras já ditas. E é nesse jogo entre paráfrase e polissemia, entre o mesmo e o diferente, entre o já dito e o a se dizer que os sujeitos e os sentidos se movimentam, fazem seus percursos, (se) significam. (ORLANDI, 2009, p.36).

Não há discurso que não se relacione com outro, os sentidos são resultado de relações que se estabelecem entre o discurso dito, os que o sustentam e dizeres futuros. Como afirma Orlandi (2009, p.39) "um dizer tem relação com outros dizeres realizados, imaginados ou possíveis".

No contexto do funcionamento da linguagem, o efeito metafórico apresenta-se como deslizamento de sentido, como possibilidade de interpretação decorrente da relação da memória, dos processos de identificação do sujeito em suas ações, em suas falhas, em sua incompletude. Em suma, "transferência significa ressignificação, historicização dos sentidos em que se simbolizam o mesmo e o diferente" (ORLANDI, 1999:15).

No que tange ao processo de significação do não verbal, o trabalho no âmbito da $\mathrm{AD}$ nos permite a descrição e análise da imagem a partir da sua própria materialidade sem perpassar pelo verbal. É pensar o não verbal como discurso independente da sua relação com o verbal.

Neste artigo, nosso objetivo é entender como o não verbal se constitui em discurso nos enunciados de protestos e como ele é utilizado mui- 
tas vezes para apoiar discursos verbais. Desta maneira, analisamos como os artefatos imagéticos (bandeiras, máscaras, entre outros) são empregados pelo manifestante para transmitir suas demandas sociais e políticas.

A interpretação da imagem como discurso pressupõe a relação com a cultura, o social, o histórico e a formação social dos sujeitos (SOUZA, 2012). A imagem significa, assim como o verbal, a partir de sua historicidade e de seu caráter de incompletude.

Para o trabalho com o não verbal, Souza (2001) propõe o conceito de policromia em paralelo ao conceito de polifonia (DUCROT, 1987) com o objetivo de compreender a tessitura do não verbal em termos discursivos, além de pensar o funcionamento dos implícitos e do silencio na relação com a imagem.

O imagético, tal como o linguístico, também suscita memórias, suscita outros dizeres e que permitem o deslizamento de sentidos a partir do já dito, do que já aconteceu, e que se encontra guardado na memória. É como assegura Souza (2000, p.143) “à imagem é reservado o papel de inscrever materialmente o acontecimento, colocando-se em jogo uma passagem do visível - o acontecimento - ao nomeado - a memória, a história".

$\mathrm{Na}$ relação imagem e memória, Courtine (2013) estabelece que toda a imagem se inscreve em uma cultura visual, que supõe a existência de uma memória visual. Portanto, não há imagem que não faça surgir outras imagens, imagens vistas anteriormente ou mesmo imaginadas.

Davallon (1999), por sua vez, entende a imagem como objeto cultural que funciona como operador da memória social em virtude da sua eficácia simbólica.

(...) a imagem é antes de tudo um dispositivo que pertence a uma estratégia de comunicação: dispositivo que tem a capacidade, por exemplo, de regular o tempo e as modalidades de recepção da imagem em seu conjunto ou emergência de significação. É um dispositivo, lembremo-nos, que por natureza é durável no tempo (1999, p.30).

$\mathrm{O}$ autor concebe a imagem como um dispositivo durável no tempo porque, enquanto objeto cultural, torna-se registro histórico e capaz de conservar a força das relações sociais.

Assim, o acontecimento, como acontecimento 'memorizado' poderá entrar na história (a memória do grupo poderá perdurar e se estender além dos limites físicos do grupo social que viveu o acontecimento); mas enquanto 'histórico', ele poderá se tornar, em compensação, elemento 
vivo de uma memória coletiva. Esta última adquirirá então uma outra dimensão: aquela, se podemos dizer, de uma memória societal. (DAVALLON, 1999, p.26)

O imagético, assim como as palavras, não encerra em si o sentido, o processo de significação é decorrente das condições de produção. Por conseguinte, na seção seguinte, analisamos as condições de produção das manifestações sociais que compreendem fundamentalmente os sujeitos, a situação e a memória (ORLANDI, 2009).

\section{As manifestações sociais e as condições de pro- dução}

Para este estudo, definimos manifestações sociais como ações coletivas tipicamente urbanas, associadas aos movimentos sociais, que ocorrem em espaços públicos. Manifestar-se é ir para a rua, ocupar um espaço público, o mais visível possível, e desfilar por ele (MORÁN, 2005). Na manifestação social, a população se organiza para expressar suas demandas.

As manifestações fazem parte de uma nova forma de movimento social, que se caracteriza por participação de uma maioria de jovens escolarizados, predominância de camadas médias, conexão por e em redes digitais, organização horizontal e de forma autônoma, e crítica às formas tradicionais da política da atualidade - especialmente os partidos e os sindicatos. (GOHN, 2014, p.431)

Historicamente, as ruas e praças da cidade são espaços das manifestações sociais como destaca Harvey (2013, p.33)

Foi nas ruas que os tchecos se libertaram em 1989 de opressivas formas de governança; foi na Praça da Paz Celestial que o movimento estudantil chinês buscou estabelecer uma definição alternativa de direitos; foi através de massivos comícios que a Guerra do Vietnã foi forçada a terminar; foi nas ruas que milhões protestaram contra o prospecto de uma intervenção imperialista norte-americana no Iraque em 15 de fevereiro de 2003; foi nas ruas de Seattle, Gênova, Melbourne, Quebec e Bangkok que os direitos inalienáveis à propriedade privada e da taxa de lucro foram desafiados.

$\mathrm{Na}$ atualidade, as manifestações sociais têm também o espaço virtual como lugar de reflexão, difusão de ideias e mobilização de manifestantes tendo como destino final o protesto nas ruas. Temos, portanto, mobilizações vinculadas a espaços físicos e virtuais que têm as redes sociais e a cidade como lócus de expressão e de protesto. 
Para entender como surgiram as manifestações utilizadas neste artigo, destacamos, nesta seção, as condições de produções que perpassam tais mobilizações, começando por detalhar nossas opções de recorte para elaboração da configuração desta análise.

Nosso corpus é formado por imagens de manifestações em um recorte que abarca o período de abril a agosto de 2013 na Argentina, no Brasil e na Espanha. Para a seleção das imagens destacamos manifestações que tivessem como principais características comuns: i) organização horizontal através de coletivos, sem a participação de partidos políticos ou sindicatos; ii) fossem movimentos resultantes de uma crise de representação política, com críticas ao governo vigente no que tange, principalmente, aos atos de corrupção; iii) protestos organizados via internet/ redes sociais e que tiveram como território de organização, acontecimento e reivindicação, além do espaço virtual, o urbano, com a ocupação de praças e marchas por ruas e avenidas.

No âmbito da interpretação, a história não é uma sucessão de fatos que possuem significado inerente. Os fatos requerem sentido que só pode ser apreendido no discurso. Na formulação dos sentidos, não pensamos a história como evolução e cronologia, o que importa não são datas, mas a maneira como os sentidos são produzidos e circulam (ORLANDI, 2012). Segundo Pêcheux (2010, p.78), um discurso não pode ser analisado como uma sequência linguística isolada, "é necessário referi-lo ao conjunto de discursos possíveis a partir de um estado definido das condições de produção".

Um discurso é pronunciado a partir de condições de produção dadas (Pêcheux, 2010) que, em sentido estrito, referem-se ao contexto imediato e em sentido amplo, abarcam o contexto sócio-histórico e ideológico (ORLANDI, 2009).

À continuação, enfocamos as condições de produção das manifestações sociais utilizadas para a seleção das imagens do corpus pontuando o contexto político-social de Argentina, Brasil e Espanha à época.

Em 2013, a Argentina era governada pela presidente Cristina Elisabet Fernández de Kirchner desde 2007, quando foi a primeira mulher eleita pelo voto direto no país. Em 2011, foi reeleita para mais um mandato que terminou em 2015.

Destacamos duas manifestações para a coleta do corpus deste estudo: o protesto denominado $18 \mathrm{~A}$ realizado no dia 18 de abril e o $8 \mathrm{~A}$, ocorrido em 8 de agosto, ambos contra o governo nacional da presidente 
Cristina Kirchner. Em 2012, os mesmos coletivos, que convocaram as manifestações supracitadas, já haviam convocado duas outras manifestações: a $13 \mathrm{~S}$, realizada no dia 13 de setembro, e a $8 \mathrm{~N}$, no dia 8 de novembro.

A mobilização do dia 18 de abril, intitulada "Cacerolazo 18A" ("Panelaço 18A") ou simplesmente 18A, foi impulsionada pela rejeição ao projeto de reforma judicial proposto pelo governo, mas também teve como pauta a insegurança, o repúdio a corrupção e a inflação como indicaram as convocações feitas nas redes sociais.

A manifestação de agosto teve como lema "Basta de corrupción - 8A". Mais uma vez os argentinos foram às ruas para protestar contra a presidente, rejeitando uma possível reeleição, pedindo o fim da corrupção, contra a insegurança e a inflação.

Em 2013, o Brasil era governado por Dilma Rousseff eleita em 2010, após fazer parte do ministério do então presidente Luiz Inácio Lula da Silva como ministra de minas e energia e como ministra-chefe da Casa Civil. O país é sede da Copa das Confederações ${ }^{1}$ e estava em meios aos preparativos para sediar a Copa do Mundo de Futebol no ano seguinte.

As manifestações de 2013 concentraram-se nos meses de junho e início de julho e tiveram como pauta inicial contestar o reajuste do valor da tarifa de ônibus. Com protestos em sequência e ocorrendo simultaneamente em diversos estados brasileiros, o aumento das passagens foi revogado, mas as manifestações seguiram tomando as ruas com novos e variados pleitos que abarcavam temas como corrupção, gastos abusivos com a Copa do Mundo, má qualidade dos serviços públicos entre outros.

Para esta investigação, vamos nos ater aos movimentos sociais de rua ocorridos nos meses de junho e julho de 2013, no Brasil, por terem todos, inicialmente, partido de um objetivo comum: a revogação do aumento das passagens de ônibus e serem partes de uma mesma mobilização que se fragmentou pelo país.

Em 2013, o presidente do governo espanhol é Mariano Rajoy Brey. O país tem como modelo de governo uma monarquia parlamentarista que teve Rajoy nomeado pelo rei Juan Carlos em $\underline{21 \text { de dezembro de } 2011 .}$

No ano de 2013, o governo espanhol é comandado por um presidente que está sob suspeita de receber dinheiro de construtoras, companhias de seguro e de doações anônimas através do Partido Popular (PP).

\footnotetext{
${ }^{1}$ Competição de futebol realizada pela Federação Internacional de Futebol (FIFA) a cada quatro anos. Em 2013, aconteceu no Brasil entre os dias 15 e 30 de junho.
} 
Diante de casos de corrupção do governo, de cortes na educação e na saúde, foram realizados mais de 6.000 protestos no país no ano de 2013.

Dentre tantas mobilizações, foram selecionadas duas manifestações para este estudo. A primeira, convocada sob o lema "Que se vayan ellos", no dia 7 de abril de 2013, protestava contra o desemprego, a precariedade e o exílio laboral. A segunda, nomeada "Barbacoa de chorizos" (Churrasco de ladrões), exigia a demissão imediata do presidente do governo, Mariano Rajoy, e foi realizada no dia 18 de julho de 2013.

A marcha do dia 7 de abril teve como objetivo principal denunciar o exílio forçado de milhares de jovens espanhóis que, por não terem emprego no seu país, são obrigados a buscar trabalho em países estrangeiros. A manifestação foi convocada pelo grupo Juventud sin futuro, que surgiu em Madri em 2011 e trabalha com temáticas jovens em diferentes perspectivas. As mobilizações ocorreram não só em cidades da Espanha como Madri, Barcelona, Zaragoza e Palma, mas também em outras vinte cidades de todo o mundo.

A manifestação do dia 18 de julho ocorreu diante das sedes do PP (Partido Popular) em diferentes cidades espanholas com o objetivo de lutar contra a corrupção e pedir a demissão do governo. A motivação para o protesto foram as declarações do ex-tesoureiro do partido, Luis Bárcenas, que afirmou, na Audiência Nacional (tribunal com sede em Villa de Madrid que tem jurisdição em todo o território espanhol), que o partido recebia grandes doações de empresas e que vários altos cargos do partido cobravam propina.

Passemos às análises com foco na presença do não verbal nas manifestações.

\section{0 não verbal em análise nos protestos de rua}

Nessa seção, nosso objetivo é analisar as diferentes formas com que os manifestantes se valem do não verbal para expressarem suas demandas em protestos na Argentina, no Brasil e na Espanha. Temos, portanto, movimentos com características semelhantes, mas com cenários diferentes e com memórias discursivas distintas. Numa perspectiva discursiva, nosso objetivo é analisar o processo de construção de dizeres não verbais sob determinadas condições: as manifestações.

Ressaltamos que as interpretações propostas são apenas uma possibilidade, pois como afirma Orlandi $(2013$, p.3) 
A interpretação é aberta e a significação sempre incompleta em seus processos de apreensão. Há ineditismo em cada análise, e isto faz a riqueza da análise de discurso, seu caráter aberto e dinâmico. O objeto da análise é inesgotável face à possibilidade da compreensão dos processos discursivos possíveis. Com a análise não se objetiva interpretar o objeto submetido a ela, mas compreendê-lo em seu modo de significar. Assim, a análise não é sobre um objeto propriamente, mas sobre o processo discursivo de que ele é parte.

Voltando-nos para o não verbal nas manifestações de rua, temos a máscara facial como um artefato presente e que, em termos discursivos, significa e contribui para a expressão da demanda do sujeito-manifestante.

Na Figura 1, o manifestante se expressa através de uma gama variada de recursos verbais e não verbais em um jogo de complementaridade no qual materialidades discursivas diferentes se coadunam em um trabalho de produção de sentido. O discurso verbal e não verbal atuam em um processo de complementaridade gerando um discurso outro.

Figura 1: Máscara de porco

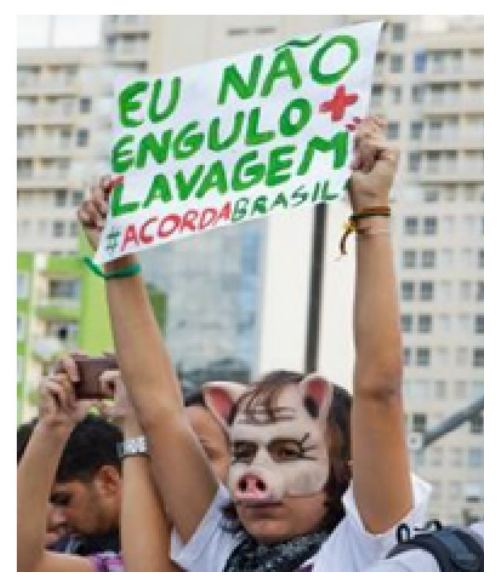

Fonte: [http://www.ricardosetti.com/manifestacoes-cartazes-de-manifestantes -mostram-a-grande-diversidade-de-reivindicacoes-e-protestos/]

O termo "lavagem", numa relação de contiguidade, se associa à "comida de porcos" por causa da máscara usada pela manifestante. O verbal complementa e explicita a opção da máscara utilizada no protesto. Por "lavagem" associada à comida de porcos, temos resto de comidas misturadas e fervidas. Mas de que lavagem está se falando? 
Falamos do substantivo "lavagem" estendido lexicalmente à ação de "lavar dinheiro", procedimento usado para disfarçar a origem de recursos ilegais. Nesse caso, o protesto estaria relacionado a não aceitação da corrupção, uma das frequentes pautas das manifestações ocorridas em junho no Brasil.

No contexto político atual, o enunciado do cartaz nos remeteria à Operação Lava-Jato, deflagrada em março de 2014, que investiga um grande esquema de lavagem e desvio de dinheiro envolvendo a Petrobras, grandes empreiteiras do país e políticos. Temos, neste caso, um deslizamento de sentido promovido pelo contexto atual.

No aspecto imagético, temos cores diferentes com o uso do vermelho para talvez realçar o imperativo utilizado em "acorda" e o sinal de + para substituir o advérbio de intensidade "mais".

O não verbal também está presente no uso do símbolo \# (hashtag) que parece chamar a população ao diálogo em um ambiente virtual. Temos, portanto, a relação entre sujeitos sendo atravessada pelo digital.

A Figura 2 mostra dois manifestantes fantasiados de presidiários e usando máscaras que representam a presidente da Argentina à época (2013), Cristina Kirchner, e seu marido Néstor Kirchner, falecido em outubro de 2010. Néstor presidiu a Argentina de 2003 a 2007 e durante seu governo foi alvo de denúncias de enriquecimento ilícito.

Figura 2: Alegorias na manifestação

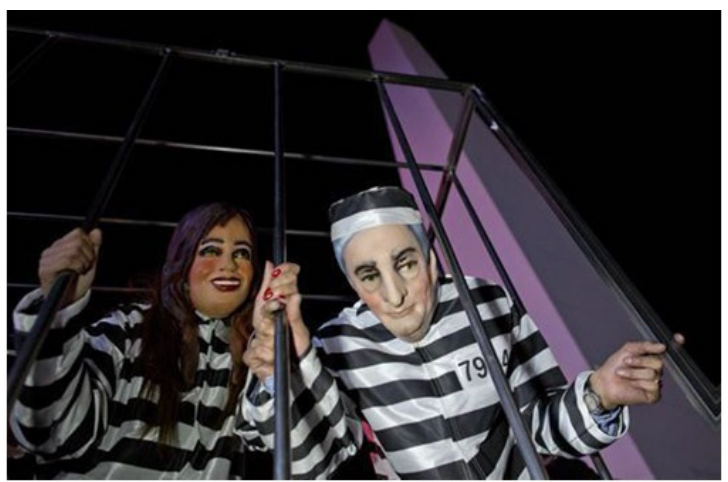

Fonte: [http://www.lanacion.com.ar/1608804-cacerolazo-8a]

Cristina, eleita para substituir o marido na presidência, governou o país em dois mandatos no período de 2007 a 2015. Em setembro de 2018, a ex-presidente teve sua prisão decretada acusada de ter recebido propina 
de empresários por obras públicas, mas, como ocupa o posto de senadora, sua prisão precisa de aprovação do Congresso.

$\mathrm{Na}$ imagem, vemos uma prisão cenográfica, na qual dois manifestantes com as máscaras supracitadas representam o casal Kirchner preso. As máscaras nos permitem identificar Néstor e Cristina, mas os trajes de presidiário e a cela são fundamentais para explicitar o discurso de protesto, em forma de alegoria.

Temos a carnavalização do protesto, que é explicitada através do uso de máscaras e também de fantasias. O termo Carnavalização, delineado por Bakhtin pela primeira vez no livro Problemas da Poética de Dostoiévski em 1929, é a transposição do espírito carnavalesco para a literatura e outras manifestações culturais. O carnaval, segundo o autor russo, representa um conjunto de manifestações da cultura popular medieval e do Renascimento que eram atos simbólicos contra a cultura oficial e que tinham como elemento comum o cômico.

$\mathrm{O}$ denominador comum de todas as características carnavalescas que compreendem as diferentes festas é a sua relação essencial com o tempo alegre. Por toda parte onde o aspecto livre e popular se conservou, essa relação com o tempo e, consequentemente, certos elementos de caráter carnavalesco, sobreviveram. (BAKHTIN, 2013, p.191)

Para uma obra ser considerada carnavalesca deve estar "marcada pelo riso, que dessacraliza e relativiza as coisas sérias, as verdades estabelecidas, e que é dirigido aos poderosos, ao que é considerado superior. Nela aliam-se a negação (a zombaria, o motejo, a gozação) e a afirmação (a alegria)" (FIORIN, 2008: 96).

Ao pensar esteticamente nos elementos carnavalescos da Idade Média e também da contemporaneidade, podemos comparar o elemento cênico da prisão utilizado na manifestação com os carros alegóricos dos desfiles de carnaval. Há uma teatralização da demanda do manifestante, que expressa através do não verbal o seu protesto.

Ricci (2010: 9) declara que "uma festa carnavalizada é uma transgressão autorizada, que rebaixa as autoridades, banaliza o poder instituído, cria novas identidades". Podemos perceber essas características presentes também na manifestação (Figura 2) onde os manifestantes assumem novas identidades, através do uso de máscaras e fantasias, com o objetivo de explicitar o que pensam sobre os últimos presidentes argentinos. Há uma transgressão permitida em um protesto. É aceitável, é esperado que autoridades sejam questionadas e que, nesses contextos sejam 
depreciadas, sejam destronadas, como vemos na Figura 2.

Nos cartazes da Figura 3, o jogo polissêmico se efetua através de uma complexa relação entre o verbal e o não verbal.

Figura 3: Máscara e cartaz

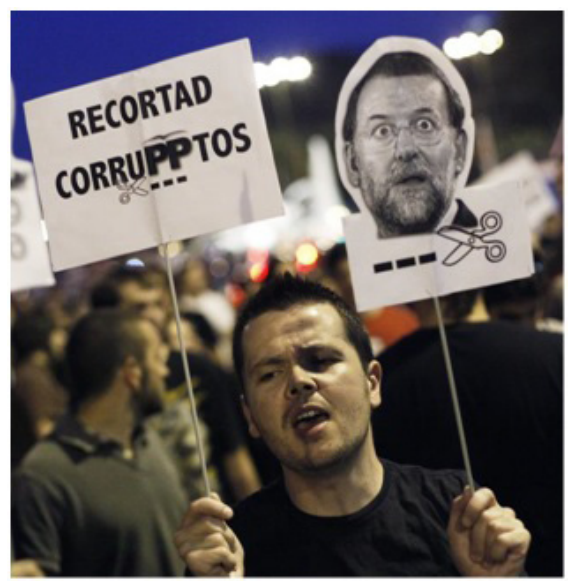

Fonte: [http://www.huffingtonpost.es/2013/07/18/barbacoa-chorizos-protestas -pp_n_3618419.html]

Os cartazes foram utilizados na manifestação realizada no dia 18 de julho depois que o ex-tesoureiro do Partido Popular da Espanha (PP) declarou que este havia sido financiado irregularmente nos últimos anos e que o presidente do governo e do partido, Mariano Rajoy, cobrava propina.

A convocatória lançada na internet tinha como proposta ocupar o espaço citadino em frente às sedes dos partidos no país e também nas embaixadas (no caso de manifestantes que estavam fora da Espanha) para protestar contra a corrupção e pedir a saída de Rajoy do governo espanhol.

$\mathrm{Na}$ imagem, podemos ver o manifestante levando dois cartazes. $\mathrm{O}$ da direita mostra o rosto do presidente do governo espanhol e do PP, Mariano Rajoy, e a imagem de uma tesoura seguindo linhas pontilhadas em uma indicação a instruções de recorte. O cartaz, explicitamente, oferece instruções para cortar a cabeça do presidente do governo espanhol, o que pode representar não o seu assassinato de fato, mas a sua saída do cargo que ocupa no governo espanhol. Inclusive essa era a principal motivação da manifestação do dia 18 de julho, exigir a renúncia de Rajoy. 
Pensando no já dito, a imagem sugerindo o corte da cabeça do presidente do governo espanhol nos remete ao enunciado "Cortem as cabeças", proferido pela Rainha de Copas, personagem do livro "Alice no País das Maravilhas" de Lewis Carroll. A personagem tem como principal característica ordenar a pena de decapitação ao menor sinal de contrariedade. A inversão promovida simbolicamente pelo manifestante nos permite pensar na relação entre manifestações social e o carnaval. A festa popular se caracteriza pela lógica das coisas ao avesso, ao contrário, em um mundo ao revés (BAKHTIN, 2013), o que também ocorre na manifestação, onde é o povo que manda cortar cabeças e não aqueles que detêm o poder.

Analisando o cartaz da esquerda, observa-se, na parte superior, o verbo "Recortad", forma imperativa afirmativa do verbo "recortar" que faz uma alusão aos "recortes" ('cortes' em português) feitos pelo governo espanhol em verbas para a saúde e educação visando conter a crise no país. O imperativo tem a função de exortar os interlocutores (representado pela $2^{\mathrm{a}}$ pessoa do plural "vosotros") a cortarem os corruptos. Mais uma vez temos a lógica do mundo ao revés do carnaval, período de subversão da ordem social estabelecida que se apresenta na manifestação quando é o povo que dá ordens. "O carnaval era o triunfo de uma espécie de liberação temporária da verdade dominante e do regime vigente, de abolição provisória de todas as relações hierárquicas, privilégios, regras e tabus" (BAKHTIN, 2013, p.8).

A sequência do cartaz explicita quais "Corruptos" devem ser "cortados", os corruptos do PP como define a escrita modificada da palavra "corruPPtos" associada a imagem da tesoura e do pontilhado abaixo das letras do partido. Há um emprego da visualidade que ao fundir a palavra "corrupto" com a sigla do partido político (PP) indica onde está a corrupção: no Partido Popular.

Nas manifestações sociais de rua, as bandeiras de partidos e sindicados sempre estiveram presentes, entretanto, nas mobilizações atuais, é comum encontrar manifestantes utilizando a bandeira nacional. A bandeira é o principal símbolo de um país e como símbolo nacional estabelece-se como marca de identificação de uma nacionalidade, como elemento que identifica o indivíduo como pertencente a uma nação.

No contexto das manifestações, a bandeira é empregada pelos manifestantes e acaba sendo ressignificada como elemento de protesto. Uma das características dos protestos argentinos é a presença de enormes bandeiras levadas pelos manifestantes coletivamente como se pode observar na Figura 4. 
Figura 4: Bandeira Argentina

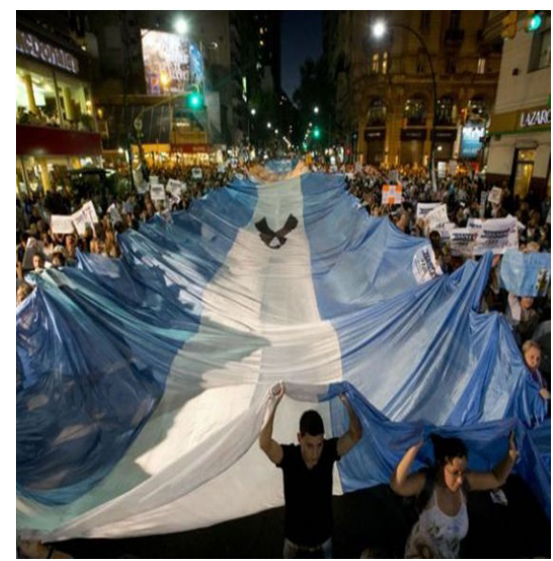

Fonte: [http://fotos.starmedia.com/2013/04/protestas-en-argentina-533100.html]

Nesse contexto, a textualização do político ocorre por meio da materialidade não verbal em dois gestos de interpretação da bandeira na manifestação argentina. Em um primeiro gesto, temos o símbolo nacional utilizado em sentido parafrástico. Como elemento exclusivamente imagético, identifica uma coletividade, surgindo como símbolo de união entre os manifestantes e possibilitando a integração: manifestação, manifestantes e nação. Pode-se entrever um sentimento de pertencimento a um grupo, um sentimento de identidade comum, um sentimento de ser argentino; sentimentos que impulsionam o manifestante no ato de protestar.

Ao analisar, ainda, a Figura 4, podemos perceber que a presença da bandeira na manifestação não é somente evocação de um sentimento de identidade nacional coletiva, mas é também elemento de protesto ao apresentar uma fita preta no lugar do Sol de Maio, emblema nacional.

A fita preta, representativa do luto, é ressignificada nas condições de produção da manifestação social em questão. Por efeito metafórico, temos um deslizamento de sentido permitindo a leitura da fita não como um símbolo de luto, mas como um elemento representativo da rejeição dos manifestantes a presidente Kirchner.

Na Figura 5, há também uma fusão entre o(s) manifestante(s) e a bandeira nacional, mas, para entender o uso da bandeira no protesto brasileiro, deve-se resgatar as condições de produção das manifestações de junho/julho no país que foram duramente reprimidas pelas forças policiais. 
Figura 5: Bandeira Brasil

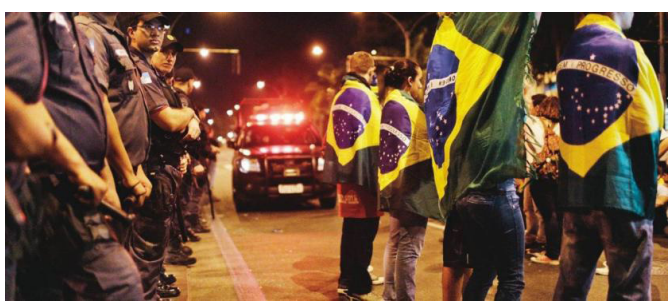

Fonte: [https://oglobo.globo.com/brasil/bandeira-do-brasil-tem-aumento-de-vendas -ganha-status-de-icone-pop-9027619]

No caso da Figura 5, temos o ato final de uma mobilização que reuniu 300 mil manifestantes e deixou cerca de 62 feridos no Centro do Rio de Janeiro. Na imagem, vemos quatro manifestantes enrolados na bandeira nacional e posicionados diante de um corredor de policiais. Houve uma ressignificação do símbolo nacional que, ao ser utilizado como capa e escudo de proteção, torna-se instrumento para tentar conter a violência policial apelando para um sentimento de nação e de identidade nacional.

Na Figura 6, a bandeira nacional espanhola, ao apresentar a junção do verbal e não verbal, transforma-se em um cartaz de protesto e não mais um símbolo de expressão de patriotismo.

Figura 6: Bandeira Espanhola

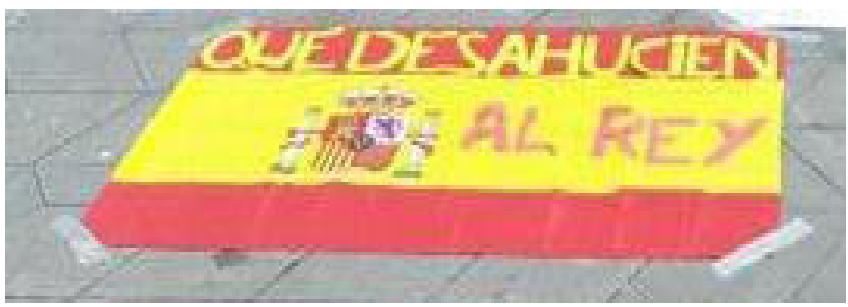

Fonte: [https://twitter.com/search?q=\%230ueSeVayanEllos7A]

A bandeira da Figura 6 foi presa no chão por um grupo de espanhóis que tiveram que emigrar para a Dinamarca por não conseguirem uma colocação no mercado de trabalho. O enunciado verbal "Que desahucien al rey" que significa 'Que despejem o rei' faz alusão ao grande número de ordens de despejos ocorridos no país após o fim da bolha imobiliária 
e que ocasionou cerca de 115 despejos por dia somente no ano de 2012, segundo estudo do "Colegio de Registradores de España".

$\mathrm{O}$ enunciado redigido na bandeira nacional nos permite identificar como expressões do manifestante a reprovação ao despejo de milhões de espanhóis e, consequentemente, o repúdio às instituições bancárias responsáveis por tais ações. Alinhado a esses posicionamentos, podemos observar também uma rejeição à Família Real na solicitação de despejo do rei e da monarquia.

\section{Conclusão}

Três países e um estudo sobre o não verbal nas manifestações sociais de rua. No meio de tantas imagens, vozes, memórias e discursos não foi nosso objetivo fazer comparações diretas, mas, a partir de uma pequena amostra, observar a rede imagética que estrutura o discurso dos movimentos de protestos.

Nas manifestações atuais temos um sujeito-manifestante que ocupa dois espaços de mobilização: o virtual e o real. $\mathrm{O}$ ambiente virtual é onde o manifestante organiza, convoca e divulga, todavia é no espaço urbano que a manifestação de fato se concretiza. É para esse momento que o manifestante se prepara, para ocupar as ruas e praças e para fazer visível a sua demanda. Por isso, é tão importante ver e ser visto.

Como breve conclusão, assinalamos que o imagético presente nas manifestações sociais não está no não verbal em si, nem na sua junção com o verbal, mas sim nas práticas político-ideológicas que expressam um descontentamento com o poder vigente. Assim, as imagens não significam pelo conteúdo que projetam, significam pela sua (in)visibilidade.

as imagens não são visíveis, tornam-se visíveis a partir da possibilidade de cada um projetar as imagens possíveis, que, necessariamente, não compõem a estrutura visual do texto não verbal em si, mas que compõem a rede de imagens mostradas, indiciadas, implícitas, metaforizadas ou silenciadas. (SOUZA, 2001, p.73).

No mais concluímos na certeza de que esta foi apenas uma interpretação entre outras tantas possíveis. 


\section{REFERÊNCIAS}

BAKTHIN, Mikhail. A cultura popular na Idade Média e no Renascimento: o contexto de François Rabelais. São Paulo: Hucitec, 2013.

Problemas da poética de Dostoiévski. Rio de Janeiro: Forense Universitária, 2015.

BRANDÃO, Helena H. Nagamine. Introdução à análise do discurso. Campinas: UNICAMP, 2004.

COURTINE, J. J. (1984). Definição de orientações teóricas e construção de procedimentos em Análise do Discurso. Policromias: Revista de estudos do discurso, imagem e som, Rio de Janeiro, v. 01, n. 1, p. 14-35, jun. 2016.

zes, 2013.

Decifrar o corpo - Pensar com Foucault. Petrópolis, RJ: Editora Vo-

DAVALLON, Jean. A imagem, uma arte de memória? In: Achard, P. et al., Papel da Memória. Campinas: Pontes, 1999.

DUCROT, Oswald. O dizer o dito. Campinas: Pontes, 1987.

FIORIN, José Luiz. Introdução ao pensamento de Bakhtin. São Paulo: Ática, 2008.

GOHN, Maria da Glória. A sociedade brasileira em movimento: vozes das ruas e seus ecos políticos e sociais. Cad. CRH [online]. 2014, vol.27, n.71, pp.431-441. Disponível em: <http://dx.doi.org/10.1590/S0103-49792014000200013>. Acesso em: 20 mar. 2017.

HARVEY, David. A liberdade da cidade. In: MARICATO, Ermínia (et al.). Cidades rebeldes: Passe Livre e as manifestações que tomaram conta do Brasil. São Paulo: Boitempo: Carta Maior, 2013.

MORÁN María Luz. Viejos y nuevos espacios para la ciudadanía: la manifestación del 15 de febrero de 2003 en Madrid. Política y Sociedad. Madrid, v.42, n.2, 2005. Disponível em: <http://www.ucm.es/BUCM/revistas/cps/11308001/articulos/POSO0505230095A.PDF>. Acesso em: 03 mar. 2017.

ORLANDI, Eni Pulcinelli. A materialidade do gesto de interpretação e o discurso eletrônico. In. DIAS, Cristiane. Formas de mobilidade no espaço e-urbano: sentido e materialidade digital [online]. Série e-urbano. Vol. 2, 2013, Disponível em: < https://www.labeurb.unicamp.br/livroEurbano/volumeII/>. Acesso em: 13 set. 2017.

Interpretação, autoria, leitura e efeitos do trabalho simbólico. $6^{\mathrm{a}} \mathrm{ed}$. Campinas: Pontes, 2012. 
. A linguagem e seu funcionamento. Campinas, SP: Pontes, 2011.

. Análise de Discurso: princípios e procedimentos. $8^{\mathrm{a}}$ ed. São Paulo: Pontes, 2009.

. As formas do silêncio. Campinas: UNICAMP, 2007.

. O próprio da análise do discurso. In: Discurso e política. Escritos no 3 . Campinas: Labeurb, 1998b.

. Segmentar ou recortar. In. Linguística: questões e controvérsias. Uberaba, 1984, p. 9-26.

. [1983] Ler o arquivo hoje. In: ORLANDI, Eni Puccinelli. (org.). Gestos de leitura: da história no discurso. 3. ed. Campinas(SP): Editora da UNICAMP, 2010.

PECHÊUX, Michel. [1975] Semântica e discurso: uma crítica à afirmação do óbvio. Trad. Eni P. Orlandi [et al.]. 4ª ed. Campinas: UNICAMP, 2006.

. [1983] Ler o arquivo hoje. In: ORLANDI, Eni Puccinelli. (org.). Gestos de leitura: da história no discurso. 3. ed. Campinas(SP): Editora da UNICAMP, 2010 .

\section{Pontes, 1999.}

. Papel da Memória. In: Achard, P. et allii. Papel da Memória. Campinas:

RICCI, Rudá. A carnavalização da política brasileira. Revista Espaço Acadêmico. No106. Março 2010. Disponível em: <http://www.periodicos.uem.br/ojs/ index.php/EspacoAcademico/article/viewFile/9414/5307>. Acesso em: jul 2017. SOUZA, T. C. C. de. O papel da imagem na constituição da memória. In: SILVA, Telma Domingues; SOUZA, T.C.C.; AGUSTINI, Carmen (org.). Imagens na comunicação e discurso. São Paulo: Annablume; Belo Horizonte: Fapemig, 2012.

. A análise do não verbal e os usos da imagem nos meios de comunicação.

Ciberlegenda, $\mathrm{n}^{\circ}$ 06, 2001.

. Carnaval e memória: das imagens e dos discursos. Contracampo, Niterói: 5, UFF, 2000.

Recebido em: 30/09/2018

Aceito em: 21/03/2019 